\title{
Patterns of Cell and Fiber Vulnerability in the Mesostriatal System of the Mutant Mouse Weaver. II. High Affinity Uptake Sites for Dopamine
}

\author{
S. Roffler-Tarlov, ${ }^{1}$ D. Pugatch, and A. M. Graybiel ${ }^{2}$ \\ 'Program in Neurosciences, Tufts University School of Medicine, Boston, Massachusetts 02111, and 2Department of Brain \\ and Cognitive Sciences, Massachusetts Institute of Technology, Cambridge, Massachusetts 02139
}

\begin{abstract}
Weaver (gene symbol wv) is an autosomal recessive mutation in the mouse that causes the death of neurons in the cerebellum and of dopamine-containing neurons in the midbrain. In the accompanying paper and in previous reports, the selective nature of the deficit produced by the gene in the dopamine-containing systems has been described after analysis of the patterns of the residual innervation in the striatum and the patterns of cell death in the midbrain. In the present report, we describe deficits in the terminals of the mesostriatal system occurring prior to a detectable dopamine deficiency in the striatum and prior to the onset of cell death in the mesencephalic dopamine-containing neurons during development. We have also found deficits in the remaining terminals of the adult weaver's striatum after the weaver pattern of innervation has been permanently established.
\end{abstract}

Axonal terminals in the caudoputamen are impaired in weaver mice at postnatal day 7 , before the onset of dopamine depletion in the caudoputamen and cell death in the midbrain. The impairment was revealed by a markedly deficient high-affinity uptake for ${ }^{3} \mathrm{H}$-dopamine by synaptosomes prepared from the caudoputamen. Throughout the remainder of development and in adulthood, the extent of the deficit in ${ }^{3} \mathrm{H}$-dopamine uptake was always greater than that for dopamine content. No striatal region was completely spared the effects of the gene. In the nucleus accumbens of the weavers, where dopamine content is normal, ${ }^{3} \mathrm{H}$-dopamine uptake was reduced by $35 \%$ in the synaptosomal preparations. In the olfactory tubercle, dopamine levels were reduced by $44 \%$ but $3 \mathrm{H}$-dopamine uptake was reduced by $60 \%$. We conclude that nerve terminals may be an initial site of vulnerability for the weaver defect and that at adulthood surviving dopamine-containing terminals in weaver animals are affected by the weaver gene. These findings may be helpful in uncovering the molecular link between the effects of the weaver gene as they are expressed in dopaminecontaining mesostriatal projections and those expressed in the cerebellum.

\footnotetext{
Received Apr. 26, 1989; revised Aug. 25, 1989; accepted Aug. 30, 1989.

This work was supported by NIH Grant NS20181 and the Whitaker Health Sciences Fund. S.R.-T. is a recipient of a Rescarch Scicntist Development Award (MH00655). D. P. was the recipient of a Parkinson's Disease Foundation Summer Fellowship and is now a medical student at McGill University. We thank Miss Baby Martin and Miss Kim Wyche for excellent technical assistance.

Correspondence should be addressed to Suzanne Roffler-Tarlov, Ph.D., Program in Neurosciences, Tufts University, 136 Harrison Avenue, Boston, MA 02111 .

Copyright (C) 1990 Society for Neuroscience $0270-6474 / 90 / 030734-07 \$ 02.00 / 0$
}

The loss of endogenous dopamine in mice that carry the mutant gene weaver $(w v)$ is remarkably selective. Within the mesostriatal system as a whole, nigrostriatal fibers are more affected than the mesolimbic innervation, and there is further specificity of loss within the nigrostriatal system (see accompanying paper). The nucleus accumbens, a mesolimbic target, suffers no detectable loss of dopamine in weaver, although anatomical methods show some loss of dopamine- and tyrosine hydroxylase (TH)-positive fibers there (Doucet et al., 1988, 1989; see accompanying paper, Graybiel et al., 1990). Both the dopamine content and TH-positive fibers are reduced in the olfactory tubercle (Roffler-Tarlov and Graybiel, 1986). Loss of TH-positive neurons and Nissl-stained neurons is striking in the dopaminecontaining cell complex of the midbrain (Schmidt et al., 1982; Gupta et al., 1987; Roffler-Tarlov et al., 1987b; Smith et al., 1988; Triarhou et al., 1988a; see accompanying paper, Graybiel et al., 1990).

Measurements of the endogenous dopamine in the striatum during postnatal development suggest that the concentrations of dopamine in week-old weavers are not significantly different from normal control mice in any region (Roffler-Tarlov and Graybiel, 1987). The 7-d-old weaver's caudoputamen also displays a qualitatively normal anatomical distribution of its catecholamine-containing innervation. In histofluorescence preparations and in sections stained for TH-like immunoreactivity, brightly fluorescent and TH-positive islands appear in a dimly fluorescent and weakly immunostained matrix. Furthermore, normal numbers of TH-positive cells are found in the 7-d-old weaver's midbrain (Roffler-Tarlov et al., 1987a). A deficit in dopamine content in the weaver's caudoputamen becomes detectable during the second week of postnatal life. The development of the dopamine-containing innervation of the caudoputamen lags behind that of the normal controls throughout the first postnatal month so that when the animals are adults, the weaver's caudoputamen contains only about $30 \%$ of the normal content of dopamine. Anatomical analysis of the weaver's caudoputamen shows a retarded development of TH-containing neuropil in the dorsolateral matrix and a disappearance, by maturity, of TH-positive fibers both in the matrix and in the dopamine islands in the same region. These studies suggest that the deficit in dopamine observed in weaver mice at maturity reflects both a failure of full development of the dopaminecontaining innervation of the striatal matrix and a degeneration of part of the dopamine-containing innervation present at the time of birth.

Our studies of both the striatum and the midbrain in weaver have emphasized the selective patterns of cell death in the dopamine-containing systems. However, neither the biochemical 
nor the anatomical experiments tested the functional capacity of the dopamine-containing terminals of the young weaver's striatum prior to the onset of cell death. Nor have the biochemical and anatomical studies tested whether the functional capacity of the surviving dopamine-containing terminals in the adult weaver's striatum is normal or whether even these dopamine-containing terminals are abnormal. Recently, Doucet and colleagues $(1988,1989)$ have reported an abnormal anatomical appearance of fibers in the adult weaver's caudoputamen labeled in vitro by incubating slices in ${ }^{3} \mathrm{H}$-dopamine. In the study reported here and briefly elsewhere (Roffler-Tarlov et al., 1987a; Roffler-Tarlov and Graybiel, 1988b), we have used synaptosomal preparations to test the functional capacity of dopamine-containing terminals from affected and unaffected regions of the weaver's striatum to accumulate ${ }^{3} \mathrm{H}$-dopamine. We analyzed separately for the adult mice the 3 main districts of the striatum: the caudoputamen, nucleus accumbens, and olfactory tubercle. In another set of experiments in which immature mice were examined, we assessed the capability of the high-affinity uptake system for dopaminc in the caudoputamen of mutant and control animals at weekly intervals during the first postnatal month beginning at postnatal day 7 .

The results of these experiments reveal pathology in residual dopamine-containing axons in the mature weaver's striatum, as well as pathological changes in nigrostriatal axons that occur during development before alterations in other dopamine-related characteristics are detectable.

\section{Materials and Methods}

Animals. Homozygous normal $(+/+)$ and homozygous weaver $(w v / w v)$ mice were used for these studies. All mice were on $\mathrm{C}_{57} \mathrm{Bl} / 6 \mathrm{JLe}-\mathrm{A}^{\mathrm{wJ}} \times$ $\mathrm{CBA} / \mathrm{CaGnLeF}$ hybrid background. All of the $w v / w v$ animals and some of the $+/+$ animals were the offspring of heterozygote breeding pairs purchased from the Jackson Laboratory, Bar Harbor, ME and maintained in the laboratory colony. Some adult $+1+$ animals used in the studies were the progeny of known $+/+$ pairs on the same background also from the Jackson Laboratory. Although the clinical phenotype for weaver is inherited as a recessive gene, much of the histopathology and also the neurotransmitter-related defects are inherited in a semidominant manner (Rezai and Yoon, 1972; Rakic and Sidman, 1973a, b; Roffler-Tarlov and Turey, 1982; Roffler-Tarlov and Graybiel, 1986; Herrup and Trenkner, 1987). Therefore, care was taken to employ only $+1+$ animals as controls to avoid possible heterozygote effects. The animals were adults (2-8 months old) and 7-, 14-, and 21-d-olds. The $w v / w v$ animals $14 \mathrm{~d}$ old and older were clearly identifiable both by their ataxia, hind-limb weakness, and tremor and by the small size of the cerebellum in these mice (Sidman et al., 1965; Sidman, 1968). The 7-dold $w v / w v$ mice and $+/ w v$ animals of all ages were distinguished from each other and from their $+1+$ littermates by differences in the size, shape, and weight of their cerebella (Rezai and Yoon, 1972; Rakic and Sidman, 1973a, b; Roffler-Tarlov and Turey, 1982).

Preparation of synaptosomes and measurement of ${ }^{3} \mathrm{H}$-dopamine accumulation and endogenous dopamine. The animals were anesthetized with sodium pentobarbitol (Nembutal, $40 \mathrm{mg} / \mathrm{kg}$, i.p.) and perfused transcardially with ice-cold $0.1 \mathrm{M}$ PBS to remove blood and to harden the brain prior to sectioning (Zigmond and Ben Ari, 1976). Each brain was placed on the stage of a tissue sectioner, encased in a $4 \%$ agar solution cooled to about $37^{\circ} \mathrm{C}$, and then sliced into a series of $420-\mu \mathrm{m}-$ thick transverse sections. The sections were illuminated from below and viewed with a stereomicroscope to identify anatomical landmarks. Each striatal region was removed bilaterally from each section in which it appeared according to previously established guidelines (Roffler-Tarlov and Graybiel, 1986). The samples of caudoputamen were collected from single animals but samples of nucleus accumbens and olfactory tubercle included tissue from 3 animals because these structures singly were too small to provide a sufficient quantity of synaptosomes for quantitative assessment of ${ }^{3} \mathrm{H}$-dopamine accumulation. The experiments were performed over a 2-year-long period when the opportunity arose to obtain a sufficient number of age-matched pairs of mice at all the ages needed.
Homogenates enriched for synaptosomes were made by homogenizing tissues in 30 volumes of ice-cold $0.32 \mathrm{~m}$ sucrose using a Teflon pestle-glass mortar pair (Gray and Whittaker, 1962). The homogenate was centrifuged for $10 \mathrm{~min}$ at $1000 \times g$ at $4^{\circ} \mathrm{C}$ to remove nuclei and debris. Aliquots of the synaptosome-containing crude supernatant were taken for the dopamine uptake measurements, measurement of endogenous dopamine, and measurement of protein. Aliquots of $50 \mu \mathrm{l}$ of the supernatant were diluted with Krebs-Ringer phosphate buffer (pH 7.2) and were gently agitated at $37^{\circ} \mathrm{C}$ in a water bath (Coyle and Snyder, 1969). Nonspecific uptake was determined using nomifensine, a potent inhibitor of dopamine uptake (Hunt et al., 1974; Dubocovich and Zahniser, 1985). The nomifensine was a gift from Hoechst-Roussel Pharmaceuticals (Somerville, NJ). After an initial $2 \mathrm{~min}$ incubation with either $50 \mu \mathrm{M}$ nomifensine or vehicle, the synaptosomes were incubated for another $2 \mathrm{~min}$ in the presence of $.05 \mu \mathrm{M}{ }^{3} \mathrm{H}$-dopamine (New England Nuclear; specific activity, $10.6-34.4 \mathrm{Ci} / \mathrm{mmol}$ ).

After incubation, the synaptosomes were isolated on $45 \mu \mathrm{m}$ filters under mild vacuum. The filters were then dissolved in counting vials containing acid, scintillation fluid was added, and the radioactivity of the samples was determined by liquid scintillation counting. The accumulation of ${ }^{3} \mathrm{H}$-dopamine by synaptosomes was linear for varying concentrations of synaptosomes and for a concentration range for dopamine of from 0.025 to $0.10 \mu \mathrm{M}$ and for incubation periods of 1-6 min. Nonspecific uptake of ${ }^{3} \mathrm{H}$-dopamine assessed by nomifensine averaged $5 \%$ of total uptake and was approximately equal to the accumulation of ${ }^{3} \mathrm{H}$-dopamine by the sucrose vehicle containing no synaptosomes. All samples taken for synaptosomal accumulation of ${ }^{3} \mathrm{H}$-dopamine were assessed in triplicate. The data for ${ }^{3} \mathrm{H}$-dopamine accumulated were calculated as counts $/ \mathrm{min} / \mathrm{mg}$ protein and were averaged for the triplicate samples and converted to pmol dopamine/mg protein $/ 2 \mathrm{~min}$. The protein content of aliquots of each synaptosomerich supernatant prepared from each of the 3 striatal regions was determined according to the method of Lowry et al. (1951).

Dopamine was extracted from aliquots of the synaptosome-rich supernatant by homogenization in equal volumes of $0.2 \mathrm{~N} \mathrm{HClO}_{4}$. After centrifugation, catecholamines in the supernatant were partially purified by alumina column chromatography as described previously (RofflerTarlov et al., 1984). Subsequently, the dopamine in the column eluate was isolated and quantitated by high-performance liquid chromatography followed by electrochemical detection (Moyer and Jiang, 1978). The recovery of catecholamine was monitored by the addition of a synthetic catechol, 3,4-dihydroxybenzylamine, as an internal standard to each sample before homogenization. The recovery of the synthetic catechol averaged $75 \%$. The results were not corrected for recovery.

Statistical analysis of the data for dopamine uptake and dopamine content was performed both for samples from individual weaver-control pairs (littermates or matched for age) and for the set of samples for weaver-control pairs at each age for the developmental study of caudoputamen for each striatal division for the adults. The mean differences calculated by pair were similar to the differences between the overall means for the 2 sets. The mean values \pm SEM are reported by set, and these were used to calculate confidence limits (2-tailed Student's $t$-test). These values are shown in Tables 1 and 2 . The data were illustrated (Figs. 1,2) by expressing the values for weaver samples as percentages of controls summed across experiments.

\section{Results}

Endogenous dopamine and ${ }^{3} \mathrm{H}$-dopamine uptake capacity of synaptosomes prepared from caudoputamen of normal and weaver mice during postnatal development

On postnatal day (P) 7, the concentration of endogenous dopamine in the synaptosomal fractions of homogenates prepared from the weaver caudoputamen was $100 \%$ of that found in controls (Table 1, Fig. 1). At each subsequent age tested, the dopamine content of the weaver's caudoputamen had failed to increase normally, so that at P14, P21, P30 (Table 1, Fig. 1), and adulthood (Fig. 2), the discrepancy between the dopamine content of control and weaver grew wider. This outcome was essentially the same as reported earlier for animals in which dopamine was extracted from acid homogenates of caudoputamen (Roffler-Tarlov and Graybiel, 1987). 


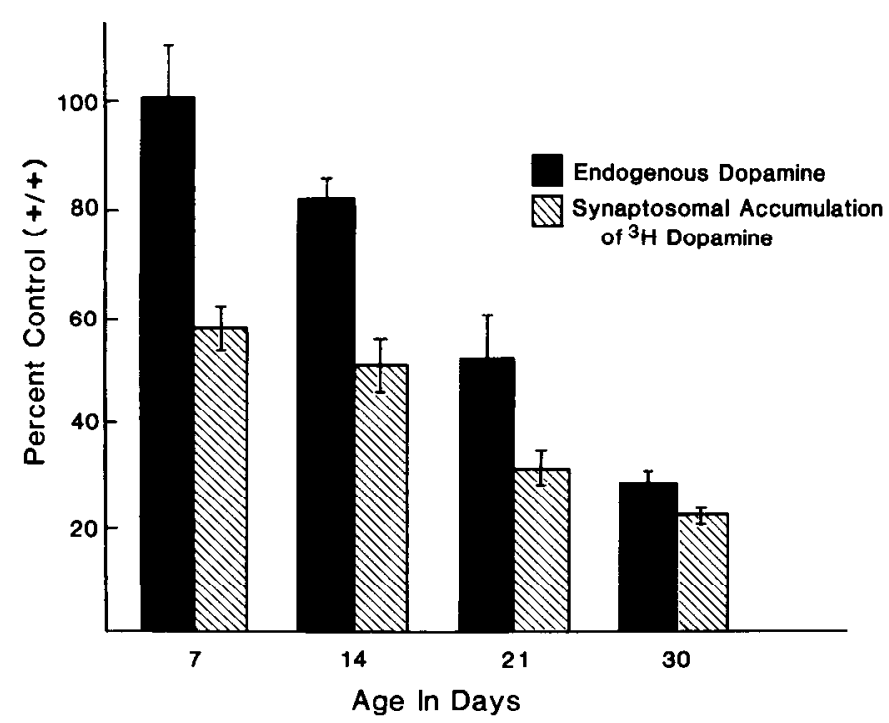

Figure 1. Comparison of endogenous dopamine in and accumulation of ${ }^{3} \mathrm{H}$-dopamine by synaptosomal preparations made from the caudoputamen of weaver mice $7,14,21$, and $30 \mathrm{~d}$ old. Data are expressed as percentages of control values. Controls are $+/+$ littermates or age matched $+/+$ mice. Between 4 and 9 animals of each genetic type were examined in each age group.

In contrast to the equivalence of the content of endogenous dopamine in synaptosomes from the P7 weaver and control caudoputamen, the capacity for accumulation of ${ }^{3} \mathrm{H}$-dopamine by synaptosomes from weavers was only $57 \pm 5 \%$ of control values (Fig. 1, Table 1). An even greater discrepancy between the capacity for accumulation of ${ }^{3} \mathrm{H}$-dopamine by weaver and control synaptosomal fractions was found for caudoputamenal samples collected at successive weeks during postnatal development (Fig. 1). At P14, the dopamine content of the synaptosomal preparations from weaver caudoputamen was reduced to $82 \pm 4 \%$ of normal values. At the same age, ${ }^{3} \mathrm{H}$-dopamine uptake in weaver caudoputamen was reduced to $51 \pm 5 \%$ of control values (Table 1, Fig. 1). At P21, synaptosomes from weaver caudoputamen contained $52 \pm 10 \%$ of the dopamine of preparations from $+/+$ animals (Table 1 , Fig. 1), whereas the accumulation of ${ }^{3} \mathrm{H}$-dopamine by these synaptosomes from weaver was reduced to $31 \pm 3 \%$ of normal values. $\Lambda t 1$ month of age, when the normal controls achieved adult values of dopamine in the synaptosomal fractions, the values for weavers were $28 \pm 2 \%$ of normal. At the same time, the values for the

Table 1. Effects of the weaver gene on the developing caudoputamen: capacity of synaptosomes to accumulate ${ }^{3} \mathrm{H}$-dopamine and the content of endogenous dopamine in the synaptosomal fraction at 4 postnatal ages in homozygous normal $(+/+)$ and homozygous $(w v / w v)$ mice

\begin{tabular}{|c|c|c|c|c|}
\hline \multirow{2}{*}{$\begin{array}{l}\text { Age in } \\
\text { days }\end{array}$} & \multicolumn{2}{|c|}{$\begin{array}{l}\text { Uptake of }{ }^{3} \mathrm{H} \text {-dopamine } \\
\text { (pmol } / \mathrm{mg} \text { protein } / 2 \mathrm{~min})\end{array}$} & \multicolumn{2}{|c|}{$\begin{array}{l}\text { Endogenous dopamine } \\
\text { (pmol/mg protein) }\end{array}$} \\
\hline & $+1+$ & $w v / w v$ & $+1+$ & $w v / w v$ \\
\hline 7 & $41 \pm 4$ & $23 \pm 2^{h}$ & $110 \pm 7$ & $111 \pm 13$ \\
\hline 14 & $43 \pm 6$ & $23 \pm 2^{a}$ & $201 \pm 17$ & $164 \pm 9$ \\
\hline 21 & $84 \pm 11$ & $26 \pm 5^{h}$ & $265 \pm 37$ & $137 \pm 28^{b}$ \\
\hline 30 & $58 \pm 6$ & $12 \pm 1^{a}$ & $418 \pm 16$ & $120 \pm 11^{t}$ \\
\hline
\end{tabular}

$a p<0.001$.

${ }^{b} p<0.01$.

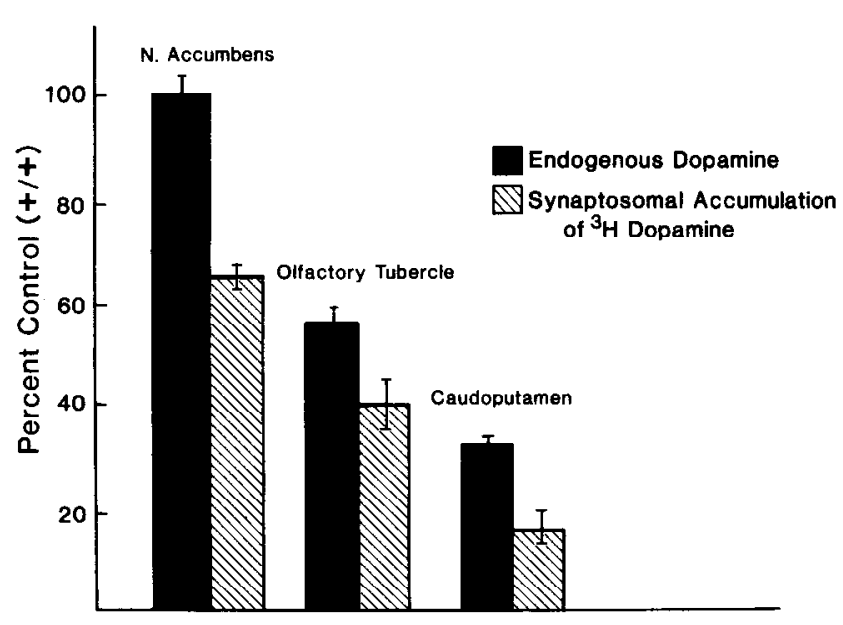

Striatal Region

Figure 2. Comparisons of dopamine content and the accumulation of ${ }^{3} \mathrm{H}$-dopamine by synaptosomes prepared from caudoputamen, olfactory tubercle, and nucleus accumbens of weaver adults. All values are expressed as percentages of controls $(+/+$ littermate or age-matched $+1+$ animals). Each sample of synaptosomes from olfactory tubercle and nucleus accumbens used for the ${ }^{3} \mathrm{H}$-dopamine uptake studies consisted of tissues from 3 animals. Each synaptosomal sample of caudoputamen was from a single animal. The means were calculated from 4-15 samplcs. Samples are from adult animals ranging in age from 2 to 9 months.

accumulation of ${ }^{3} \mathrm{H}$-dopamine by the weaver synaptosomal fractions was $22 \pm 1 \%$ of normal (Table 1, Fig. 1).

As shown in Figure 2, the deficit in uptake capacity for ${ }^{3} \mathrm{H}$ dopamine persisted in older weavers and continued to exceed the deficit in endogenous dopamine content. In the adult weaver caudoputamen, the content of endogenous dopamine in the synaplosomal preparations was $32 \pm 1 \%$ of control, whereas the capacity for ${ }^{3} \mathrm{H}$-dopamine uptake was $17 \pm 2 \%$ of control (Table 2, Fig. 2).

\section{Endogenous dopamine and ${ }^{3} \mathrm{H}$-dopamine accumulation by synaptosomes prepared from nucleus accumbens, olfactory tubercle, and caudoputamen of adult weaver and normal animals}

In agreement with our previous measurements from acid-extracted tissue homogenates (Roffler-Tarlov and Graybiel, 1986), analysis of synaptosomal fractions prepared from the weaver nucleus accumbens demonstrated normal amounts of dopamine in this striatal region (Table 2). Despite the normal dopamine

Table 2. Effects of the weaver gene in 3 striatal regions of adult mice: capacity of synaptosomes to accumulate ${ }^{3} \mathbf{H}$-dopamine and the content of endogenous dopamine in the synaptosomal fractions in homozgyous normal $(+/+)$ and homozygous weaver $(w v / w v)$ mice

\begin{tabular}{|c|c|c|c|c|}
\hline \multirow[b]{2}{*}{ Striatal region } & \multicolumn{2}{|c|}{$\begin{array}{l}{ }^{3} \mathrm{H} \text {-dopamine uptake } \\
\text { (pmol } / \mathrm{mg} \\
\text { protein } / 2 \mathrm{~min} \text { ) }\end{array}$} & \multicolumn{2}{|c|}{$\begin{array}{l}\text { Endogenous dopamine } \\
\text { (pmol/mg protein) }\end{array}$} \\
\hline & $+1+$ & $w v / w v$ & $+/+$ & $w v / w v$ \\
\hline Caudoputamen & $35 \pm 3$ & $6 \pm 1^{a}$ & $496 \pm 23$ & $159 \pm 5^{a}$ \\
\hline Olfactory tubercle & $35 \pm 5$ & $14 \pm 1^{b}$ & $209 \pm 15$ & $163 \pm 9^{a}$ \\
\hline N. accumbens & $25 \pm 1$ & $16 \pm 2^{b}$ & $386 \pm 14$ & $392 \pm 12$ \\
\hline
\end{tabular}


content, uptake of ${ }^{3} \mathrm{H}$-dopamine was reduced to $65 \pm 2 \%$ of normal values in synaptosomal fractions from weaver nucleus accumbens (Table 2, Fig. 2). The concentration of dopamine in synaptosomal fractions prepared from weaver olfactory tubercle was $56 \pm 3 \%$ of control values. The capacity for ${ }^{3} \mathrm{H}$-dopamine uptake was even more severely reduced, to $40 \pm 5 \%$ of the $+/+$ values (Fig. 2, Table 2).

The values expressed as percent control for the weaver's nucleus accumbens and olfactory tubercle are plotted together with those for the caudoputamen in Figure 2. The defects in the accumulation of ${ }^{3} \mathrm{H}$-dopamine show the same rank order as the defects in dopamine content (the nucleus accumbens being least affected and caudoputamen most affected), but the degree of deficit for each structure is greater for dopamine uptake, the limiting case being the nucleus accumbens, which has no perceptible abnormality in the content but a $35 \%$ loss in uptake capacity.

\section{Discussion}

Two important conclusions emerge from this study. First, the earliest and most severe actions of the weaver gene on the mesostriatal system appear to be directed towards the terminals of the dopamine-containing neurons. Second, although the effects of the weaver gene discriminate in degree between nigrostriatal and mesolimbic systems, there may be no wholly invulnerable part of the dopamine-containing mesostriatal system.

Uptake capacity and storage capacity of dopamine-containing terminals

At all ages studied, the capacity of synaptosomal fractions from the weaver's caudoputamen to accumulate ${ }^{3} \mathrm{H}$-dopamine was even more compromised than the content of endogenous dopamine in the same synaptosomal preparation. A vivid discrepancy between the values of the 2 dopamine system-related parameters occurred at $7 \mathrm{~d}$ of age when ${ }^{3} \mathrm{H}$-dopamine uptake in the weaver's caudoputamen was reduced to $57 \%$ of normal values, whereas the content of endogenous dopamine was still not significantly different from that in normal controls. The principle of greater damage to uptake capacity than to the content of endogenous dopamine extended to the ventral striatum. In the olfactory tubercle, ${ }^{3} \mathrm{H}$-dopamine uptake was reduced by $60 \%$ relative to that in controls, whereas endogenous dopamine was reduced by $44 \%$ compared with control values. In the nucleus accumbens, where endogenous dopamine content is entirely spared in weavers of all ages, the uptake capacity of the synaptosomal preparations was reduced by $35 \%$ relative to control values.

\section{Uptake deficit in the ventral striatum}

An amended view of the consequences of the weaver gene for dopamine-containing mesostriatal systems is necessary. The brunt of the damage inflicted is borne by the nigrostriatal systcm, but both systems suffer a decline in terminal function as measured by accumulation of ${ }^{3} \mathrm{H}$-dopamine, even in ventral striatal regions in which quantitative measurement shows dopamine content to be normal or nearly so.

As has been demonstrated in earlier reports, no damage to the nucleus accumbens of weaver mice is betrayed at any age by quantitative measurement of endogenous dopamine (RomlerTarlov and Graybiel, 1984, 1986, 1987). Both Doucet et al. $(1988,1989)$ and ourselves (see accompanying paper) have noted, however, an abnormal appearance of the dopamine-con- taining innervation of the lateral part of the nucleus accumbens region. The dissections carried out for the nucleus accumbens samples in the present analysis, as in our past studies, included the entire medial part of the nucleus accumbens and part of the core: the knife cuts separating the caudoputamen and nucleus accumbens were made along a straight line from the foot of the lateral ventricle to the medial edge of the anterior commissure (see Roffler-Tarlov and Graybiel, 1984). The dissection protocol was identical for the measurements of dopamine content and ${ }^{3} \mathrm{H}$-dopamine uptake. The fact that dopamine content in the nucleus accumbens was normal but ${ }^{3} \mathrm{H}$-dopamine uptake was subnormal therefore cannot reasonably be attributed to a sampling bias. The measurements are more likely to be accurate reflections of a difference in total content and total uptake capacity of the tissue.

It is less straightforward to interpret the apparent disparity between normal dopamine content of the nucleus accumbens samples and the apparent depletion of TH-like and dopaminelike immunoreactivity in the lateral part of the region (see accompanying paper). Conceivably, there was up-regulation of dopamine in the medial part of the nucleus accumbens sufficient to offset the lateral depletion. However, it is certain that our dissection leaves part of what is defined as the "core" or lateral nucleus accumbens with the ventral caudoputamen. Thus, it is likely that a lateral deficit may have been masked by normal medial values because only a small part of the lateral region is included in our nucleus accumbens sample and because the dopamine-containing innervation is much more dense in the medial than in the lateral part of the nucleus accumbens, even normally. In the olfactory tubercle, the deficit in ${ }^{3} \mathrm{H}$-dopamine uptake was paralleled by dopamine depletion. Our previous anatomical observations have shown that the loss of innervation is most severe in, and possibly restricted to, the lateral half of the olfactory tubercle. This topography of loss of dopaminecontaining innervation is similar to that now recognized for the nucleus accumbens. It is worth emphasizing that the functional capacity of dopamine terminals in each affected striatal region appears more severely damaged than dopamine storage in these regions.

\section{Pathologic origins of the dopamine uptake deficit in the weaver striatum}

High-affinity uptake of dopamine is a characteristic of dopamine-containing terminals in the brain and has the physiological function of terminating the action of released dopamine by recapturing it for storage or metabolism in the presynaptic terminal. The reduced capacity to accumulate ${ }^{3} \mathrm{H}$-dopamine seen here in synaptosomal preparations from the weaver's striatum could be caused by a number of different pathological alterations. Fewer dopamine-containing fibers may exist in the nucleus accumbens of adult weavers and in the 7-d-old weaver's caudoputamen despite the normal content of dopamine of these structures. Such an explanation demands the existence of compensatory mechanisms in residual fibers to account for the normal transmitter content. Compensation of this type does not occur in similar conditions in which pathology has been created acutely by the neurotoxin 6-hydroxydopamine. In this circumstance, dopamine-containing terminals are destroyed in proportion to parallel and equivalent declines of endogenous dopamine in ${ }^{3} \mathrm{H}$-dopamine uptake in the striatum (Iversen and Uretsky, 1970; Zigmond et al., 1984). Similarly, administration of 1-methyl-4-phenyl-1,2,5,6-tetrahydropyridine (MPTP) to 
mice results in an equivalent decrease in ${ }^{3} \mathrm{H}$-dopamine uptake and in endogenous dopamine content (Heikkila et al., 1984).

An alternative interpretation that is more readily compatible with the observed normal dopamine content in the week-old weaver caudoputamen is that in early development, dopaminecontaining terminals may be present in normal numbers, and synthesis and storage of transmitter may not be compromised, even though uptake capacity is already subnormal. It is also possible that dopamine uptake is down-regulated in the face of altered synthesis and depletion resulting in the potentiation of the effects of released dopamine. These interpretations would fit well with our findings from cell counts in the midbrain of neonatal weavers: at P7, no decrease in TH-positive cells is apparent despite the major loss of such neurons at adulthood (Roffler-Tarlov et al., 1987b, and unpublished observations).

Given the early appearance of the uptake deficit found in the weaver's caudoputamen and the severe reduction in uptake borne by residual axons in adult weavers, a parsimonious interpretation of our findings is that the pathological alterations in dopamine uptake represent a fundamental defect in the disease. When the terminal defects are severe enough, they may result in the death of subpopulations of the neurons located in the dopamine-containing cell groups of the midbrain.

The finding of axonal pathology in the dopamine-containing systems in weaver suggests a link to pathology occurring in the granule cell in the cerebellum of this mutant. The cerebellar granule cells, which fail to migrate postnatally in weaver, are direct cellular targets of the weaver gene, as shown by studies of chimeric animals (Goldowitz and Mullen, 1982; Goldowitz, 1989) and as strongly suggested by studies of weaver and normal granule cells and glial cells in reciprocal cocultures (Hatten et al., 1986). Like the dopamine-containing systems of the striatum, there are also marked regional differences in vulnerability in the cerebellum to the action of the gene (Herrup and Trenkner, 1987). Observations of cultured granule cells from early postnatal mice show that, as in vivo, large numbers of granule cells from weaver mice die, whereas those cultured from normal mice have a much higher survival rate (Willinger et al., 1981; Willinger and Margolis, 1985a, b; Hatten et al., 1986).

Neurite development on the part of the surviving granule cells from weavers is known to be markedly different from that of normal granule cells in 3 ways (Willinger and Margolis, 1985a, b). First, the incidence of neurite initiation detectable by timelapse photography is increased among the weaver's granule cells. Second, neurite elongation is severely impaired in the weaver's granule cells in both those that are destined to die and those that survive. The neurites of weaver's granule cells are less than $20 \%$ as long as those from the control's granule cells. Third, the morphology of the weaver's neurites is characterized by an uneven thickness, which contrasts with the slender cylinders formed by the controls' neurites. A description of the processes of cultured dopamine-containing neurons from weavers is not yet available. Our present observations, however, point to severe functional disability of these axonal processes, immunohistochemistry suggests that the nigrostriatal neuropil has an abnormal distribution (Graybiel et al., 1988; Triarhou et al., 1988b; and accompanying paper), and the studies of Doucet et al. (1988, 1989), in which the residual dopamine axons in the weaver's striatum are viewed autoradiographically after incubation with ${ }^{3} \mathrm{H}$-dopamine, suggest abnormally thin and spindly nigrostriatal axons in the weaver striatum. If, as our observations here suggest, the terminal dysfunction is an early and primary defect, the effects of the weaver gene on neurites might be key both in the striatum and in the cerebellum.

These considerations suggest that a step in the genetic pathway regulating the development of cell membrane components of both cerebellar granule cells and mesencephalic dopamine-containing neurons may be affected by thc mutant gene weaver. Among these 2 neuronal populations, however, there may be no fully spared subdivisions, even though subpopulations of both cell types die and others survive despite the pathology evident in their processes. An interesting further possibility is that the neurons affected by the weaver mutation may not be limited to cerebellar granule cells and the dopaminergic mesencephalic neurons, but may include a wide variety of cells as yet undiscovered as cellular targets because of the subtle nature of the defect. Within the cerebellum, for example, the weaver gene is known to affect the viability of a subpopulation of Purkinje cells as well as granule cells, and these Purkinje cells may be an additional primary cellular target of the gene (Herrup and Trenkner, 1987; D. Goldowitz, personal communication). Conceivably, the defect wherever it appears may result from the absence of a key molecule necessary for many or all cells during a restricted developmental time window. An essential neuronglial contact may be involved. In this light, an important clue may be found in the observed requirement of astroglial-derived fibroblast growth factor for successful process outgrowth by cerebellar granule cells (Hatten et al., 1988). In this case, neuronal systems would be vulnerable because of their developmental stage rather than because of their identities within particular neural systems per se. Alternatively, overexpression of a molecular species leading to toxicity might play a key role in the pathology of the neurites and their terminals (Collins and Olney 1982).

\section{The weaver nigrostriatal defect in relation to MPTP-induced toxicity}

Additional clues for the cause of cell death in weaver may be provided by the mechanisms of neurotoxins. We have noted a strong resemblance between the disease expressed in the weaver's mesostriatal system and that produced in mice after the administration of the neurotoxin MPTP (Roffler-Tarlov and Graybiel, 1988a). The similarities between the condition produced by the neurotoxin and that produced by the mutant gene in the midbrain are introduced here because it is possible that both could have an origin in direct effects on dopamine-containing terminals resulting in retrograde degencration. To summarize the similarities briefly, both the weaver gene and high doses of the neurotoxin administered to adult mice produce permanent depletion of dopamine (Roffler-Tarlov and Graybiel, 1986; Ricaurte et al., 1987; Saitoh et al., 1987), and greater vulnerability is shown by the nigrostriatal pathway than by the mesolimbic system (Roffler-Tarlov and Graybiel, 1984; Duvoisin et al., 1986; Sundstrom et al., 1987). It follows, too, that the most severe cell loss in the dopamine-containing cell groups of the midbrain occurs in the substantia nigra in both types of mice, the ventral tegmental area being relatively, though not completely, spared in MPTP-treated mice and completely or relatively spared in weavers (Heikkila et al., 1984; Gupta et al., 1986, 1987; Roffler-Tarlov et al., 1987b, and accompanying paper; Sundstrom et al., 1987; Triarhou et al., 1988a).

Direct evidence for retrograde effects on the vulnerable neurons has been provided in studies in which MPTP was administered in the forebrain of monkeys and caused cell death in the 
midbrain (Imai et al., 1988). In mice, too, evidence points to a retrograde reaction after MPTP administration (Heikkila et al., 1985). In an autoradiographic demonstration of dopamine uptake sites in MPTP-treated mice using the ligand ${ }^{3} \mathrm{H}$-mazindol, Donnan et al. (1987) found pronounced deficits in uptake in MPTP-treated mice. These were most severe in the terminal regions of the nigrostriatal neurons, whereas the cell bodies were much more resistant. Only a $15 \%$ reduction in ${ }^{3} \mathrm{H}$-mazindol binding occurred in mesencephalic dopamine-containing cells of MPTP-treated mice, whereas reductions amounting to nearly $60 \%$ took place in dorsolateral regions of caudoputamen.

Pathological alteration of dopamine-containing terminals is thus a characteristic of the striatum both in weavers and in the MPTP-treated animals, though it is not known to what extent the pathological changes are similar in detail. For the weaver mouse, the studies of ${ }^{3} \mathrm{H}$-dopamine accumulation into striatal synaptosomes described here have uncovered an early sign of pathology in axonal terminals and may also point to an initial site of vulnerability. The pathology, when severe enough, may lead eventually to retrograde changes and the ensuing death of certain of the dopamine-containing mesostriatal neurons.

It is now clear that although cell death is confined to restricted groups of dopamine-containing neurons in the midbrain, the processes of some or all of the residual neurons are affected by the weaver gene. This discrepancy raises the possibility that the mutant gene weaver affects all dopamine-containing neurons, all cerebellar granule cells, and even many other neurons and glial cells, but that because of threshold effects is lethal only to subclasses, and not to the entire population of cells in each region. More generally our findings raise the possibility that other genes thought to be specific for particular types of neurons may actually affect larger populations of cells whose relative vulnerability might differ, for example, according to the timing of expression of the gene relative to the developmental stage of the cells or the environment in which the vulnerable group is set.

\section{References}

Collins, R. C., and J. W. Olney (1982) Cortical seizures cause distant thalamic lesions. Science 218: 177-179.

Coyle, J. T., and S. H. Snyder (1969) Antiparkinsonian drugs: Inhibition of dopamine uptake in the corpus striatum as a possible mechanism of action. Science 166: 899-901.

Donnan, G. A., S. J. Kaczmarczyk, J. S. McKenzie, P. J. Rowe, R. M. Kalnins, and F. A. O. Mendelsohn (1987) Regional and temporal effects of 1-methyl-4-phenyl-1,2,3,6-tetrahydropyridine on dopamine uptake sites in mouse brain. J. Neurol. Sci. 81: 261-271.

Doucet, G., P. Brundin, S. Seth, Y. Murata, R. E. Strecker, L. Triarhou, B. Ghetti, and A. Björklund (1988) Regional density of dopamine innervation in the neostriatum of weaver mutant mouse: Effect of ventral mesencephalic grafts. Eur. J. Neurosci. Abstr. (Suppl.) 78.6, p. 307.

Doucet, G., P. Brundin, S. Seth, Y. Murata, R. E. Strecker, L. C. Triarhou, B. Ghetti, and A. Björklund (1989) Degeneration and graftinduced restoration of dopamine innervation in the weaver mouse neostriatum: A quantitative radioautographic study of $\left[{ }^{3} \mathrm{H}\right]$ dopamine uptake. Exp. Br. Res. 77: 552-568.

Dubocovich, M. L., and N. R. Zahniser (1985) Binding characteristics of the dopamine uptake inhibitor $\left[{ }^{3} \mathrm{H}\right]$ nomifensine to striatal membranes. Biochem. Pharmacol. 34: 1137-1144.

Duvoisin, R. C., R. E. Heikkila, W. J. Nicklas, and A. Hess (1986) Dopaminergic neurotoxicity of MPTP in the mouse: A murine model of parkinsonism. In Recent Developments in Parkinson's Disease, $\mathrm{S}$. Fahn et al., eds., Raven, New York.

Goldowitz, D. (1989) The weaver granuloprival phenotype is due to intrinsic action of the mutant locus in granule cells: Evidence from homozygous weaver chimeras. Neuron 2: 1565-1575.
Goldowitz, D., and R. J. Mullen (1982) Granule cell as a site of gene action in the weaver mouse cerebellum: Evidence from heterozygous mutant chimeras. J. Neurosci. 2: 1474-1485.

Gray, F. G., and V. P. Whittaker (1962) The isolation of nerve endings from brain: An electron microscope study of cell fragments derived by homogenization and centrifugation. J. Anat. (Lond.) 96: 79-88.

Graybiel, A. M., K. Ohta, and S. Roffler-Tarlov (1988) Toward a genetic analysis of the striosomal system: Patterns of nigrostriatal loss in the mutant mouse weaver. Soc. Neurosci. Abstr. 14: 1066.

Graybiel, A. M., K. Ohta, and S. Roffler-Tarlov (1990) Patterns of genetically programmed cell and fiber vulnerability in the mesostriatal system of the mutant mouse weaver: I. Gradients and compartments. J. Neurusci. 10. $720-733$.

Gupta, M., B. K. Gupta, R. Thomas, V. Bruemmer, J. R. Sladek, Jr., and D. L. Felten (1986) Aged mice are more sensitive to 1-methyl4-phenyl-1,2,3,6-tetrahydropyridine treatment than young adults. Neurosci. Lett. 70: 326-331.

Gupta, M., D. L. Felten, and B. Ghetti (1987) Selective loss of monoaminergic neurons in weaver mutant mice-An immunocytochemical study. Brain Res. 402: 379-382.

Hatten, M. E., R. K. H. Liem, and C. A. Mason (1986) Weaver mouse cerebellar granule neurons fail to migrate on wild-type astroglial processes in vitro. J. Neurosci. 86: 2676-2683.

Hatten, M. E., M. Lynch, R. E. Rydel, J. Sanchez, J. Joseph-Silverstein, D. Moscatelli, and D. B. Rifkin (1988) In vitro neurite extension by granule neurons is dependent upon astroglial-derived fibroblast growth factor. Dev. Biol. 125: 280-289.

Heikkila, R. E., A. Hess, and R. C. Duvoisin (1984) Dopaminergic neurotoxicity of 1-methyl-4-phenyl-1,2,5,6-tetrahydropyridine in mice. Science 224: 1451-1453.

Heikkila, R. E., W. J. Nicklas, I. Vyas, and R. C. Duvoisin (1985) Dopaminergic toxicity of rotenone and the 1-methyl-4-phenyl-1,2,3,6tetrahydropyridinium ion after their stereotaxic administration to rats: Implication for the mechanism of 1-methyl-4-phenyl-1,2,3,6tetrahydropyridine toxicity. Neurosci. Lett $62: 389-394$.

Herrup, K., and E. Trenkner (1987) Regional differences in cytoarchitecture of the weaver cerebellum suggest a new model for weaver gene action. Neuroscience 23: 871-885.

Hunt, P., M-H. Kannengiesser, and J-P. Raynaud (1974) Nomifensine: A new potent inhibitor of dopamine uptake into synaptosomes from rat brain corpus striatum. J. Pharm. Pharmacol. 26: 370-371.

Imai, H., T. Nakamura, K. Endo, and H. Narabayashi (1988) Hemiparkinsonism in monkeys after unilateral caudate infusion of 1 -methyl-4-phenyl-1,2,3,6-tetrahydropyridine (MPTP): Behavior and histology. Brain Res. 474: 327-332.

Iversen, L. L., and N. J. Uretsky (1970) Regional effects of 6-hydroxydopamine on catecholamine containing neurones in rat brain and spinal cord. Brain Res. 24: 364-367.

Lowry, O. H., N. J. Rosebrough, A. L. Farr, and R. J. Randall (1951) Protein measurement with the Folin phenol reagent. J. Biol. Chem. 193: 265-275.

Moyer, T. P., and N.-S. Jiang (1978) Optimized isocratic conditions for analysis of catecholamines by high performance reversed-phase paired-ion chromatography with amperometric detection. J. Chromatogr. 153: 365-373.

Rakic, P., and R. L. Sidman (1973a) Sequence of developmental abnormalities leading to granule cell deficit in cerebellar cortex of weaver mutant mice. J. Comp. Neurol. 152: 103-132.

Rakic, P., and R. L. Sidman (1973b) Weaver mutant mouse cerebellum: Defective neuronal migration secondary to abnormality of Bergmann glia. Proc. Natl. Acad. Sci. USA 70: 240-244.

Rezai, Z., and C. H. Yoon (1972) Abnormal rate of granule cell migration in the cerebellum of "weaver" mutant mice. Dev. Biol. 29: $17-26$.

Ricaurte, G. A., L. E. DeLanney, I. Irwin, and J. W. Langston (1987) Older dopaminergic neurons do not recover from the cffects of MPTP. Neuropharmacology 26: 97-99.

Roffler-Tarlov, S., and A. M. Graybiel (1984) Weaver mutation has differential effects on the dopamine-containing innervation of the limbic and nonlimbic striatum. Nature 307: 62-66.

Roffler-Tarlov, S., and A. M. Graybiel (1986) Expression of the weaver gene in dopamine-containing neural systems is dose-dependent and affects both striatal and nonstriatal regions. J. Neurosci. 6: 33193330.

Roffler-Tarlov, S., and A. M. Graybiel (1987) The postnatal devel- 
opment of the dopamine-containing innervation of dorsal and ventral striatum: Effects of the weaver gene. J. Neurosci. 7: 2364-2372.

Roffler-Tarlov, S., and A. M. Graybiel (1988a) Genetic and toxininduced depletion of striatal dopamine. In Pharmacology and Functional Regulation of Dopaminergic Neurons, P. M. Beart, G. N. Woodruff, and D. M. Jackson, eds., pp. 204-210, Macmillan, New York.

Roffler-Tarlov, S., and A. M. Graybiel (1988b) Regional effects of the weaver gene on presynaptic dopamine uptake sites in striatum. Soc. Neurosci. Abstr. 14: 1066.

Roffler-Tarlov, S., and M. Turey (1982) The content of amino acids in the developing cerebellar cortex and deep cerebellar nuclei of granule cell deficient mutant mice. Brain Res. 247: 65-73.

Roffler-Tarlov, S., S. C. Landis, and M. J. Zigmond (1984) Effects of Purkinje cell degeneration on the noradrenergic projection to mouse cerebellar cortex. Brain Res. 298: 303-311.

Rumer-Tarlov, S., D. Pugalch, and A. M. Graybiel (1987a) Early effects of the weaver gene on the dopamine-containing innervation of the dorsal striatum. Sixth International Congress for Pharmacology Abstr. .53 0308.

Roffler-Tarlov, S., A. M. Graybiel, B. Martin, and J. Kauer (1987b) The mesencephalic dopamine-containing neurons in the weaver mouse. Soc. Neurosci. Abstr. 13: 1599.

Saitoh, T., K. Niijimi, and Y. Mizuno (1987) Long-term effect of 1-methyl-4-phenyl-1,2,3,6-tetrahydropyridine (MPTP) on striatal dopamine content in young and mature mice. J. Neurol. Sci. 77:229235.

Schmidt, M. J., B. D. Sawyer, K. W. Perry, R. W. Fuller, M. M. Foreman, and B. Ghetti (1982) Dopamine deficiency in the weaver mutant mouse. J. Neurosci. 2: 376-380.

Sidman, R. L. (1968) Development of interneuronal connections in the brain of mutant mice. In Physiological and Biochemical Aspects of Nervous Integration, F. D. Carlson, ed., pp. 163-193, PrenticeHall, Englewood Clifts, NJ.

Sidman, R. L., M. C. Green, and S. H. Appel (1965) Catalog of the Neurological Mutants of the Mouse, pp. 66-67, Harvard U. P., Cambridge, MA.
Smith, D. E., M. W. Smith III, T. R. Cooper, and T. H. Joh (1988) Shifts in class distribution of TH-labeled cells in the substantia nigra of the neurological mutant mouse weaver. Soc. Neurosci. Abstr. 14. 1066.

Sundstrom, E., I. Stromberg, T. Isutsumi, L. Alson, and G. Jonsson (1987) Studies on the effect of 1-methyl-4-phenyl-1,2,3,6-tetrahydropyridine (MPTP) on central catecholamine neurons in $\mathrm{C}_{57} \mathrm{~B} 1 \%$ mice. Comparison with three other strains of mice. Brain Res. 405 . 26-38.

Triarhou, L. C., J. Norton, and B. Ghetti (1988a) Mesencephalic dopamine cell deficit involves areas A8, A9 and A10 in weaver mutant mice. Exp. Brain Res. 70: 256-265.

Triarhou, L. C., J. Norton, and B. Ghetti (1988b) Synaptic conncctivity of tyrosine hydroxylase immunoreactive nerve terminals in the striatum of normal, heterozygous and homozygous weaver mutant mice. J. Neurocytol. 17: 221-232.

Willinger, M., and D. M. Margolis (1985a) Effect of the weaver (wv) mutation on cerebellar neuron differentiation. I. Qualitative observations of neuron behavior in culture. Dev. Biol. 107: 156-172.

Willinger, M., and D. M. Margolis (1985b) Effect of the weaver (wv) mutation on cerebellar neuron differentiation. II. Quantitation of neuron behavior in culture. Dev. Biol. 107: 173-179.

Willinger, M., D. M. Margolis, and R. L. Sidman (1981) Neuronal differentiation in cultures of weaver mutant (wv) mouse cerebellum. J. Supramol. Struct. Cell. Biochem. 17: 79-86.

Zigmond, R. E., and Y. Ben-Ari (1976) A simple method for the serial sectioning of fresh brain and the removal of identifiable nuclei from stained sections for biochemical analysis. J. Neurochem. 26: 12851287.

Zigmond, M. J., A. L. Acheson, M. K. Stachowiak, and E. M. Stricker (1984) Neurochemical compensation after nigrostriatal injury in an animal model of preclinical parkinsonism. Arch. Neurol. 41: 856861 . 